\title{
Inskripsi Berhuruf Arab Di Kompleks Makam Troloyo (Kajian \\ Terhadap Gaya Penulisan, Arti dan Maksud Inskripsi, serta Kronologinya)
}

\section{Muhammad Chawari}

Keywords: tomb, majapahit, inscription, description, religion

\section{How to Cite:}

Chawari, M. (1997). Inskripsi Berhuruf Arab Di Kompleks Makam Troloyo (Kajian Terhadap Gaya Penulisan, Arti dan Maksud Inskripsi, serta Kronologinya). Berkala Arkeologi, 17(2), 52-61. https://doi.org/10.30883/jba.v17i1.761
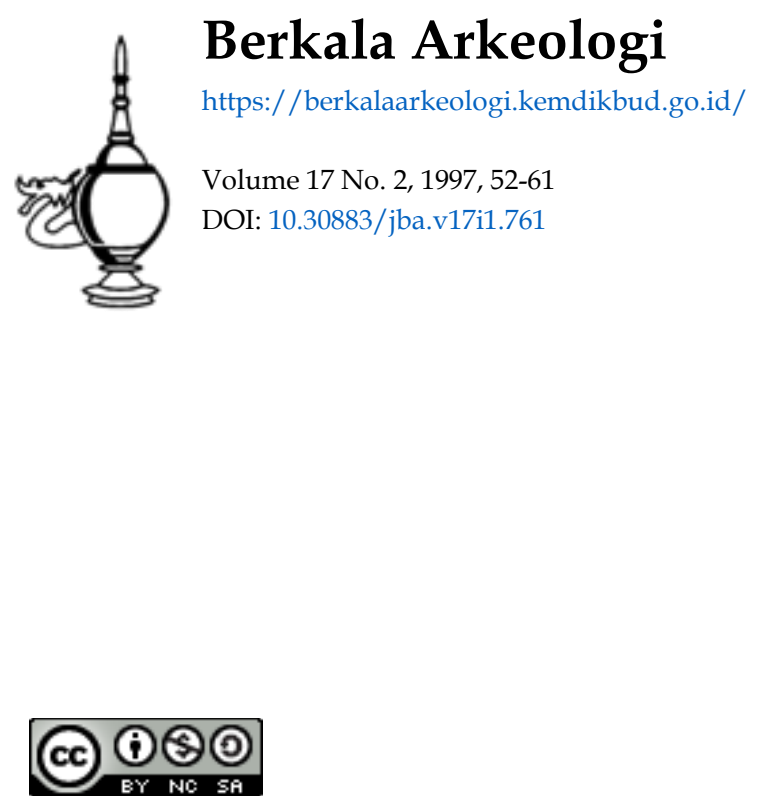

This work is licensed under a Creative Commons Attribution-NonCommercial-ShareAlike 4.0 International License. 


\title{
INSKRIPSI BERHURUF ARAB DI KOMPLEKS MAKAM TROLOYO \\ (Kajian Terhadap Gaya Penulisan, Arti dan \\ Maksud Inskripsi, serta Kronologinya)
}

\author{
Muhammad Chawari \\ (Balai Arkeologi Yogyakarta)
}

\section{PENDAHULUAN}

\section{Latar Belakang Permasalahan}

Telah diketahui bersama bahwa Kerajaan Islam pertama di Indonesia adalah Kerajaan Samudera Pasai. Keberadaan kerajaan ini didasarkan pada adanya inskripsi berhuruf Arab yang terpahat pada batu-batu nisan makam raja pertama yaitu Malik as-Salih yang wafat pada tahun $696 \mathrm{H}$ atau $1297 \mathrm{M}$ (Tjandrasasmita, 1976: 1-2), dan puteranya yang bernama Sultan Muhammad Malik az-Zahir yang wafat pada tahun $726 \mathrm{H}$ atau $1326 \mathrm{M}$ (Tjandrasasmita, 1992: 108). Periode berikutnya di Jawa muncul pula sebuah kerajaan bercorak Islam yaitu Kerajaan Demak. Kerajaan ini munculnya sekitar abad ke-15 dengan peninggalan utama berupa sebuah masjid agung dan kompleks makam raja-rajanya. Periode sekitar abad ke-15 dapat diketahui berdasarkan adanya candra sengkala (sengkalan memet) yang berupa lukisan seekor kura-kura yang terdapat pada dinding mihrab masjid Demak tersebut. Sengkalam kura-kura tersebut menurut Uka Tjandrasasmita berarti angka tahun 1401 Ç atau 1478 M (Tjandrasasmita, 1976: 6-7).

Selanjutnya peninggalan masa Islam tersebar di sepanjang pantai utara Jawa sejak dari Banten, Cirebon, Kudus, Jepara, Rembang, Tuban, Lamongan, Gresik, Surabaya, sampai Troloyo yaitu sebuah desa di pedalaman Jawa Timur tepatnya di Kabupaten Mojokerto, Jawa Timur. Hal ini dapat diketahui berdasarkan tinggalantinggalan yang ada hingga sekarang ini. Dari kota-kota seperti tersebut di atas dapat diketahui kronologi masa Islam di Jawa. J.P. Moquette salah seorang peneliti bangsa asing telah berhasil membaca tulisan pada nisan yang ada di Leran (Gresik). Nama yang berhasil direkam dari inskripsi pada nisan tersebut yaitu Fatimah binti Maimun bin Hibat Allah yang wafat pada tahun $495 \mathrm{H}$ atau 1102 M (Moquette, 1912: 208214). Kemudian pada tahun 1910 Dr. van Ronkel berhasil menelaah nisan kubur Malik Ibrahim yang ada di Gresik, selanjutnya hasil bacaannya itu diulangi lagi oleh Th. W. Juynboll. Keduanya membaca bulan wafatnya Malik Ibrahim adalah Rabi'al Awwal. Tetapi keduanya disangkal oleh Moquette yang membacanya dengan Rabi'al Akhir. Dari inskripsi yang ada pada nisan makam Malik Ibrahim tersebut diperoleh angka tahun $822 \mathrm{H}$ atau $1419 \mathrm{M}$ (Tjandrasasmita, 1992: 108). Di samping itu, di Kompleks Makam Pusponegoro juga ditemukan inskripsi dengan huruf pegon yang terdapat pada salah satu cungkup makam. Masih di Gresik yaitu di daerah Giri 
terdapat sebuah pesantren dan kompleks makam Islam kuna yang dikenal sebagai bekas pusat pengembangan agama Islam untuk wilayah Indonesia bagian timur (Hasyim Umar. 1979).

Selain iru, makam-makam yang terdapat di daerah Troloyo dan Trowulan, Kabupaten Mojokerto pernah diteliti oleh Uka Tjandrasasmita. Hasil penelitian tersebut kemudian dipublikasikan lewat Aspek-aspek Arkeologi Indonesia No. 3 Tahun 1976. Disebutkan bahwa di kedua daerah tersebut banyak ditemukan makam yang berasal dari abad XIV s.d. XVI. Dari makam-makam tersebut banyak ditemukan nisan yang berinskripsi huruf Arab. Kompleks makam Troloyo terletak di Dukuh Sidodadi, Desa Sentonorejo, Kecamatan Trowulan, Kabupaten Mojokerto. Sarjana lain yang lebih dahulu meneliti daerah ini adalah L.Ch. Damais yang tulisannnya dimuat dalam BEFEO tahun 1957. Disebutkan bahwa di daerah tersebut banyak ditemukan nisan-nisan kubur dari orang-orang muslim yang pada waktu itu bermukim di sekitar Keraton Majapahit. Sekitar 30 buah nisan dan balok batu bertulis telah diteliti oleh L.Ch. Damais. Nisan-nisan tersebut kebanyakan menyebut angka tahun dengan tahun Çaka. Angka-angka tahun tersebut sejaman dengan masa berdiri. masa kejayaan, dan masa keruntuhan Kerajaan Majapahit (Damais, 1957: 353-415).

Bangsa Indonesia pada abad 13 s.d. $18 \mathrm{M}$ pernah mengalami masa kejayaan lewat kerajaan-kerajaan Islam. Dengan demikian setidak- tidaknya akan meninggalkan bekas-bekas tinggalannya. Terutama dalam hal ini yang berkaitan dengan manusia dan masyarakat pendukungnya (masyarakat Muslim), yaitu makam. Tetapi jauh sebelum itu, yaitu pada abad $11 \mathrm{M}$ pernah ditemukan peninggalan Islam tertua (berupa makam juga) yang merupakan indikasi tentang adanya Islam di Indonesia.

Penelitian tentang tulisan pada makam-makam kuna di Indonesia telah menernukan banyak sekali data, baik nama orang yang dimakamkan, tentang kematian, pertanggalan, silsilah, kutipan ayat-ayat suci Al-Qur'an, dan beberapa bacaan dari nisan-nisan makam itu yang erat kaitannya dengan tradisi membuat tanda bagi orang yang telah meninggal dengan tulisan (khusus berhuruf dan bahasa Arab). Walaupun pembubuhan tulisan serta pemasangan tanda bagi orang yang telah meninggal masih menimbulkan pro kontra. Terlepas dari itu, sejauhmana maksud dan tujuan pembubuhan tulisan pada makam berkaitan dengan orang yang dimakamkan.

\section{Tujuan Penulisan}

Dari Kompleks Makam Troloyo dapat diketahui berbagai aspek kepurbakalaan yang berhubungan dengan gejala perkembangan Islam khususnya di Jawa Timur. lebih khusus lagi berkaitan erat dengan keberadaan Kerajaan Majapahit. Dari berbagai macam penelitian yang pernah dilakukan, baik oleh peneliti asing maupun peneliti pribumi terhadap data kronologi. data keletakan kompleks makam, data ragam hias. data inskripsi, dapat diketahui tentang nilai sejarah, nilai politik, nilai budaya. dan juga nilai agama yang melatarinya. 
Dalam tulisan ini yang akan ditampilkan hanya akan membahas nilai yang berhubungan dengan agama. Khusus nilai agama, hal ini dapat diketahui terutama dari isi inskripsi yang ada. Oleh sebab itu maka kajian yang akan dilakukan terhadap isi inskripsi dan studi terhadap paleografinya, diharapkan akan dapat mengungkap hal-hal yang berkaitan dengan maksud dan tujuan pencantuman isi dari inskripsi tersebut. Yang dimaksud dengan isi inskripsi meliputi huruf, angka. kata, dan kalimat, serta maksud dan rujuan pencantumannya.

\section{Metode Penelitian}

Untuk mempermudah tercapainya rujuan tersebut di atas, akan diterapkan sebuah metode penelitian. Metode penelitian tersebut adalah eksploratif. Metode ini bertujuan untuk mengumpulkan sebanyak mungkin data-data yang ada di lapangan. Data-data yang dimaksud adalah berupa inskripsi-inskripsi yang ada pada makam yang terdapat di kompleks Makam Troloyo.

\section{Unit Analisis}

Unit analisis dalam tulisan ini adalah seluruh makam-makam yang ada di Kompleks Makam Troloyo yang nisannya berinskripsi huruf Arab,

\section{DATA-DATA HASIL PENELITIAN}

Pada tanggal 5 s.d. 13 Agustus 1994 Balai Arkeologi Yogyakarta mengadakan penelitian dengan tema Perkembangan Paleografi Arab Tahap II. Penelitian ini direncanakan sampai lima tahap. Pada tahap ke-2 ini dilakukan di lima kabupaten, yaitu Mojokerto, Sumenep, Pamekasan, Sampang, dan Bangkalan (Chawari, 1994: 7 24). Khusus untuk penelitian di Kabupaten Mojokerto dilakukan di Kompleks Makam Troloyo.

\section{Cungkup Kubur Panjang}

Disebut Cungkup Kubur Panjang karena di dalam cungkup ini hanya terdapat sebuah makam yang panjangnya melebihi ukuran makam pada umumnya. Cungkup Kubur Panjang ini terletak di sebelah timur laut masjid. Makam tersebut adalah Makam Syeh Ngundung. Istilah Cungkup Kubur Panjang tersebut diberikan oleh masyarakat setempat. Inskripsi yang terdapat pada nisan makam merupakan kutipan ayat-ayat AlQur'an dari satu potong Surat Ali Imran ayat 185, Al-Ambiya ayat 35, Al-Ankabut ayat 57, dan dua ayat Al-Qur'an surat Ar-Rahman ayat 26 dan 27. Inskripsi yang tertera pada makam menerapkan gaya penulisan Naskhi yang cukup baik. Inskripsi ditulis secara horisontal (separo nisan bagian atas) dan vertikal (separo nisan bagian bawah).

\section{Cungkup Kubur Tunggal}

Disebut Cungkup Kubur Tunggal karena di dalam cungkup ini hanya terdapat sebuah makam. Cungkup ini terletak di sebelah timur masjid. Makam tersebut adalah Makam 
Syeh Jumadil Kubro. Istilah Cungkup Kubur Tunggal diberikan oleh masyarakat setempat. Inskripsi yang terdapat pada nisan makam merupakan kutipan ayat-ayat AlQur'an dari Surat Ali Imran ayat 185. Al- Ambiya ayat 35. Al-Ankabut ayat 57. ArRahman ayat 26, Al- Qashas ayat 88. dua kalimah dalam bahasa Arab, dan Asma'ul Khusna. Inskripsi pada makam ini menerapkan gaya dasar penulisan Sulus yang masih sederhana.

\section{Makam Petilasan Walisongo}

Disebut Makam Petilasan Walisongo karena makam ini berada dalam satu kotak (gentan. Jw) bersama delapan makam yang lain. sehingga jumlahnya ada sembilan. Makam Petilasan Walisongo ini terletak di sebelah timur masjid. Sembilan makam yang berada dalam satu kotak ini oleh masyarakat setempat disebut dengan istilah Petilasan Walisongo. Inskripsi yang terdapat pada nisan makam merupakan kutipan ayat-ayat Al-Qur'an dari Surat Ali Imran ayat 185. Al-Ambiya ayat 35, Al-Ankabut ayat 57. dan satu kalimat dalam bahasa Arab. Inskripsi yang diterapkan untuk menampilkan tulisan mempunyai gaya dasar Sulus yang sangat sederhana dan terkesan asal dapat dibaca.

\section{Cungkup Kubur Telu}

Cungkup Kubur Telu terletak di sebelah timur masjid. Istilah Cungkup Kubur Telu diberikan oleh masyarakat setempat. Disebut demikian karena di dalamnya terdapat tiga buah makam, yaitu:

\section{a. Makam Syeh Maulana Ibrahim}

Letak makam ini di dalam cungkup berada paling timur di antara tiga makam yang berada dalam satu bangunan Cungkup Kubur Telu. Inskripsi yang terdapat pada nisan makam merupakan kutipan ayat-ayat Al-Qur'an dari Surat Ar-Rahman ayat 26 dan 27. Inskripsi pada makam ini menerapkan penulisan dengan gaya dasar Naskhi sangat sederhana, namun tetap mudah dibaca.

\section{b. Makam Syeh Maulana Sekah}

Letak makam ini di dalam cungkup berada di tengah di antara tiga makam yang berada dalam satu bangunan Cungkup Kubur Telu. Inskripsi yang terdapat pada nisan makam berupa satu kalimat tauhid (dua kalimah syahadat). Inskripsi pada makam ini menerapkan gaya penulisan Sulus yang cukup indah. Penulisan dengan gaya Sulus pada nisan makam ini nampaknya merupakan penulisan yang paling indah dibandingkan dengan cara penulisan inskripsi nisan-nisan yang lain.

\section{c. Makam Syeh Abdul Qodir Jaelani Sini}

Letak makam ini di dalam cungkup berada paling barat di antara tiga makam yang berada dalam satu bangunan Cungkup Kubur Telu. Inskripsi yang terdapat pada nisan makam merupakan kutipan ayat-ayat Al-Qur'an dari satu potongan Surat Ali Imran ayat 185. Al-Ambiya ayat 35. Al-Ankabut ayat 57, puji-pujian kepada Allah. kalimat 
Tauhid. Asma'ul Khusna. Selain itu juga mencantumkan angka tahun Çaka dalam angka Arab yaitu 1533 C (1611 M). Inskripsi pada makam menerapkan penulisan dengan gaya Naskhi yang cukup baik. Tetapi karena banyaknya inskripsi yang ditampilkan sementara media penulisan (nisan) sangat terbatas maka ada beberapa kata yang sulit dibaca.

\section{Makam Tanpa Nama}

Makam ini berada atau terletak di sebelah tenggara masjid. Makam ini terkesan seperti dipisahkan dari makam-makam lainnya yang mempunyai inskripsi. Makam ini oleh masyarakat setempat tidak diberi nama, berbeda dengan makam-makam yang lainnya. Inskripsi yang terdapat pada nisan makam merupakan kutipan dari ayat-ayat Al-Qur'an dari Surat Al-Ambiya ayat 35, Al- Ankabut ayat 57, satu potong Surat Ali Imran ayat 185 , dan satu kalimat tauhid (dua kalimah syahadat). Inskripsi yang tertera pada makam menerapkan gaya penulisan dengan gaya dasar Naskhi yang sangat sederhana.

\section{KAITAN ANTARA ISI INSKRIPSI DENGAN MAKSUD DAN TUJUAN PENCANTUMANNYA}

\section{A. Penerapan Gaya Penulisan Arab}

Melihat kembali seluruh inskripsi yang ada dan diterapkan pada Kompleks Makam Troloyo dapat diketahui adanya dua gaya penulisan yang dipakai. Dua gaya penulisan Arab tersebut adalah Sulus dan Naskhi. Penulisan dengan gaya Naskhi terdapat dua katagori, yaitu gaya Naskhi yang cukup baik dan gaya Naskhi yang sangat sederhana. Sedangkan penulisan dengan gaya Sulus juga mempunyai dua katagori, yaitu gaya Sulus yang sangat sederhana dan gaya Sulus yang cukup indah. Bahkan penulisan dengan gaya Sulus dari makam Syeh Maulana Sekah merupakan yang paling indah dibandingkan dengan gaya penulisan sejenis dari makam yang lain, maupun dari jenis penulisan yang lain (Naskhi) yang ada di Kompleks Makam Troloyo.

Walaupun di Kompleks Makam Troloyo terdapat dua gaya penulisan, tetapi secara kuantitas gaya dasar Naskhi lebih banyak dipergunakan dari pada gaya Sulus. Dengan kata lain gaya dasar Naskhi lebih dominan. Tulisan dengan gaya Naskhi ini menarik bagi orang awam karena agak mudah dibaca dan menuliskannya (Safadi, 1986: 64). Penerapan gaya dasar Naskhi yang sangat sederhana, seolah-olah dimungkinkan agar supaya lebih mudah dibaca dan ditulis. Hal ini sesuai dengan tujuan pencantuman inskripsi agar dapat dibaca dan diketahui orang banyak. Terlepas dari hal tersebut, dalam hal keindahan penulisan inskripsi pada bangunan-bangunan masjid di Banten, Cirebon, Demak, Kudus, Yogyakarta atau pada nisan-nisan makam di Demak. Kudus, dan Troloyo harus dibedakan dengan yang ada pada nisan makam Maulana Malik Ibrahim (822 H/1419 M) dan makam Fatimah binti Maimun bin Hibat Allah (495 H/1102 M) yang terdapat di Gresik dan juga makam yang terdapat di daerah Samodra Pasai. Sebab berdasarkan pada penelitian yang telah dilakukan 
oleh J.P. Moquette. nisan makam yang ada di Gresik dan Samudra Pasai menunjukkan corak persamaan dengan yang ada di India. Sehingga beberapa nisan yang mempunyai kesamaan corak itu diduga berasal dari Cambay. Pendapatnya itu didasarkan atas perbandingan corak dan cara-caranya menuliskan huruf-huruf Arab serta menempatkan ayat-ayat Qur'an pada ruangan tertentu, baik pada sisinya maupun pada tempat-tempat yang diperlukan untuk tulisan itu. Selain itu juga. dalam hal penempatan kalimat-kalimat pada nisan-nisan dari Samudra Pasai yang berangka tahun $831 \mathrm{H}$ dan $822 \mathrm{H}$. Itu semua dibandingkan dengan nisan dari Umar bin Ahmad al-Kazaruni yang berasal dari tahun $734 \mathrm{H}$ di Cambay. Berdasarkan atas hal-hal tersebut di atas. Moquette menarik kesimpulan bahwa corak makam semacam itu adalah hasil buatan pabrik yang ada di Cambay, Gujarat (Tjandrasasmita. 1992: 108- 111 ).

Berdasarkan atas hal itu pula, maka penelitian yang dilakukan oleh Balai Arkeologi Yogyakarta dengan tema Perkembangan Paleografi Arab Tahap 1 yang dilakukan di daerah Gresik tidak melakukan survei terhadap makam Maulana Malik Ibrahim dan makam Fatimah binti Maimun bin Hibat Allah. Kedua makam tersebut dibuat tidak oleh dan di daerah setempat (Gresik) (Chawari, 1993: 6-16).

Secara khusus dan kaligrafis dalam hal kualitas inskripsi yang terdapat pada nisannisan di Kompleks Makam Troloyo sangat jauh berbeda dibandingkan dengan inskripsi-inskripsi yang ada di Gresik (makam Maulana Malik Ibrahim dan makam Fatimah binti Maimun bin Hibat Allah) dan Samudra Pasai. Dilihat dari bentuk huruf, cara penulisan, dan hasilnya yang kasar, diperkirakan bahwa inskripsi tersebut dikerjakan dan ditangani langsung oleh orang-orang asli Jawa. Para penulis atau pemahat ini masih terlalu asing dengan tulisan Arab, mereka hanya meniru tulisan tersebut yang pernah dikenal sebelumnya.

\section{B. Arti dan maksud isi inskripsi:}

Dari tujuh buah makam seperti diuraikan pada bab II di atas, dapat diketahui tentang adanya penggunaan atau kutipan beberapa ayat $\mathrm{Al}$-Qur'an dari beberapa surat. Ayatayat suci Al-Qur'an tersebut ada yang dikutip secara utuh, tetapi ada juga yang dikutip sepotong-sepotong saja. Beberapa surat yang dikutip baik secara utuh maupun sepotong-sepotong adalah sbb:

\section{Satu potongan dari Surat Ali Imran ayat 185}

Arti: Tiap-tiap yang berjiwa akan merasakan mati. Dan sesungguhnya pada hari kiamat sajalah disempumakan pahalamu.

\section{Satu potongan dari Surat Al-Ambiya ayat 35}

Arti: Tiap-tiap yang berjiwa akan merasakan mati.

\section{Surat Al-Ankabut ayat 57}

Arti: Tiap-tiap yang berjiwa akan merasakan mati. Kemudian hanyalah kepada Kami kamu dikembalikan. 
Arti: Semua yang ada di bumi itu akan binasa. Dan tetap kekal Dzat Tuhanmu yang mempunyai kebésaran dan kemuliaan.

\section{Surat Al-Qashas ayat 88}

Arti: Tiap-tiap sesuatu pasti binasa, kecuali Allah.

6. Selain surat-surat dalam $\mathrm{Al}-\mathrm{Qur}$ 'an, tercantum pula beberapa ungkapan sbb: dua kalimah dalam bahasa Arab, dan Asma'ul Khusna (nama-nama sifat Allah), pujipujian kepada Allah, kalimat tauhid (dua kalimah syahadat).

Maksud pemakaian angka tahun hijriyah dan penggunaan angka dan huruf Arab untuk menyatakan kalimat-kalimat tauhid (dua kalimah syahadat) seperti tercantum dalam beberapa nisan makam, pencantuman do'a-do'a, pencantuman nama-nama sifat Allah (asma'ul khusna), serta memuat puji-pujian kepada Allah. Selain itu juga petikan ayat-ayat Al-Qur'an dari Surat Ali Imran ayat 185, Surat Al-Ambiya ayat 35, Surat Al-Ankabut ayat 57, Surat Ar-Rahman ayat 26 dan 27, dan Surat Al-Qashas ayat 88 . In semua memberikan bukti bagaimana hubungan kelompok masyarakat muslim Troloyo dengan Tuhannya atau dengan agama yang mereka anut. Nisan kubur yang memuat kalimat tauhid (dua kalimah syahadatain) menunjukkan betapa pentingnya mengucapkan pengakuan atau kesaksian seseorang yang akan memeluk agama Islam. Pengakuan atau kesaksian tersebut adalah tiada Tuhan melainkan Allah dan Muhammad adalah utusan-Nya (rasul-Nya) (Tjandrasasmita, 1993: 281).

Selain itu juga mengungkapkan nama-nama sifat Allah, tentang peringatan kepada manusia bahwa semua yang ada di bumi pasti akan mengalami kematian dan kebinasaan, serta peringatan bahwa setiap manusia akan memperoleh imbalan pahala dari perbuatannya selama hidup di dunia, dan besok pada hari kiamat atau kebangkitan.

\section{Identifikasi Tokoh}

Istilah-istilah atau penamaan tokoh yang digunakan (baik untuk menyebutkan nama cungkup maupun nama tokoh yang dimakamkan) seperti tersebut di atas diberikan oleh masyarakat setempat. Penamaan atau pengistilahan yang dipakai tersebut semata-mata hanyalah untuk memudahkan identifikasi saja. Sebetulnya dengan dasar apa masyarakat menamakan tokoh-tokoh yang dimakamkan di Kompleks Makam Troloyo, belum diketahui dengan jelas. Yang jelas nama-nama seperti Syeh Jumadil Kubro, Syeh Abdul Qodir Jaelani Sini, Syeh Maulana Sekah, Syeh Maulana Ibrahim, Syeh Ngundung, dan Walisongo merupakan nama-nama tokoh yang dikenal dalam sejarah Islam. Sebab dari seluruh makam yang ada prasastinya tidak satupun yang mencantumkan nama orang yang dimakamkan. Secara khusus memang antara makam dengan nama tokoh-tokoh yang disebutkan di atas itu tidak ada hubungannya. Tetapi secara umum nama-nama tokoh tersebut pernah berjaya di masa lalu, tentunya di 
tempat lain (tidak di daerah Trowulan) dan kurun waktu yang lain pula. Dengan demikian nama-nama tokoh tersebut bukan tokoh sejarah yang berhubungan dengan makam tersebut. Selain itu, penamaan tokoh-tokoh tersebut diberikan oleh masyarakat setempat secara turun temurun.

Berkaitan dengan tidak dicantumkannya nama-nama orang yang meninggal, kemungkinan itu berhubungan atau merupakan adaptasi kelompok minoritas (masyarakat muslim) di Trowulan. Adaptasi kelompok minoritas (Islam) terhadap mayoritas (Hindu). Sebagaimana diketahui dalam Hindu tidak dikenal adanya pemakaman dengan jirat dan nisan, yang ada melalui diperabukan lewat bangunan candi. Dalam hal pendirian candi sebagai tanda penghormatan terhadap tokoh yang meninggal, tidak dikenal adanya penulisan nama tokoh yang dimaksud pada dinding bangunan candi. Kalaupun terdapat tulisan pada bangunan candi, biasanya berhubungan dengan kronologi pembengunan ataupun pemugarannya.

\section{Kronologi Makam Dalam Sejarah Majapahit}

Dari tujuh buah data pada makam yang ada di Kompleks Makam Troloyo, satu di antaranya berangka tahun $1533 \mathrm{CC}(1611 \mathrm{M})$. Sebetulnya makam-makam yang berangka tahun yang ada di kompleks makam tersebut jumlahnya banyak. Jumlah nisan dan balok batu yang berangka tahun ada 21 buah. Nisan-nisan berangka tahun tersebut kebanyakan memakai tahun çaka, meskipun ada juga yang memakai angka tahun Arab. Nisan yang memakai angka tahun Arab menyebut nama Zaenudin tahun $874 \mathrm{H}$ atau $1469 \mathrm{M}$.

Selain itu, yang menarik adalah adanya sebuah balok batu berangka tahun çaka yang menyebut angka $1204 \mathrm{C}$ atau $1282 \mathrm{M}$. Jika dilihat dari usia, maka balok batu tersebut berasal dari masa sebelum berdirinya Kerajaan Majapahit. Hal inilah yang meragukan L. Ch. Damais dan Uka Tjandrasasmita. Yang menjadi pertanyaan apakah balok batu tersebut benar-benar merupakan nisan atau hanyalah bagian dari bangunan yang bercorak Hindu (candi). Selain kedua angka tahun tersebut masih banyak lagi angka tahun çaka, yaitu 1241 C (1319 M), 1276 C (1354 M), 1278 C (1356 M), 1294 C $(1372 \mathrm{M}), 1298$ C $(1376 \mathrm{M}), 1302$ Ç $(1380 \mathrm{M}), 1319 \mathrm{CC}(1397 \mathrm{M}), 1320 \mathrm{CC}(1398$ M), 1329 C (1407 M), 1332 C (1410 M), 1340 Ç (1418 M), 1342 C (1420 M), 1349 C $(1427 \mathrm{M}), 1389$ C $(1467 \mathrm{M}), 1391$ C $(1469 \mathrm{M})$, dan 1397 C (1475) (Tjandrasasmita, 1993: 278-280).

Jika dilihat seluruh angka tahun yang ada berkisar antara $1204 \mathrm{Ç}(1282 \mathrm{M})$ yang tertua dan $1533 \mathrm{C}(1611 \mathrm{M})$ yang termuda. Angka tahun yang tertua adalah $1204 \mathrm{C}$ (1282 M) jika dicocokkan dengan sejarah berasal dari masa sebelum Majapahit. Tahun tersebut berasal dari masa pemerintahan raja Singasari yang bemama Kertanagara yang berkuasa antara tahun $1254-1292 \mathrm{M}$. Raja ini kemudian meninggal pada tahun 1214 C $(1292 \mathrm{M})$ dan diberi gelar Yang Mulia di alam Siwa Budha (Slametmulyana, 1979: 107). 
Masih berdasarkan sederetan angka-angka tahun tersebut diperkirakan bahwa kelompok masyarakat muslim pada masa puncak kekuasaan Majapahit di bawah Raja Hayam Wuruk dan Patih Gadjah Mada sudah berada di sekitar ibu kota kerajaan. Kebanyakan dari mereka bermukim di Troloyo, yaitu sebuah tempat yang terletak di selatan Kedaton. Tempat itu (Troloyo) merupakan suatu lokasi yang diberikan oleh pihak kerajaan Majapahit (Tjandrasasmita. 1993: 280). Pemberian lokasi tertentu yang terpisah kepada kelompok masyarakat muslim mempunyai dua kemungkinan. Kemungkinan pertama mempunyai maksud untuk mengucilkan, dan yang kedua sebagai sikap toleransi dalam menghormat kelompok tertentu yang minoritas. Hal ini tergantung dari sudut pandang yang mana. Jika pemberian lokasi itu diberikan oleh pihak penguasa, dapat diduga dimaksudkan untuk mengucilkan. Maksud pengucilan itu agar terpisah dari kelompok lain, terutama dalam hal menghambat penyebaran ideologi yang dianut kelompok tersebut. Tetapi inipun dapat juga berarti sifat toleransi penguasa terhadap kegiatan yang dilakukan oleh kelompok masyarakat muslim. Namun apabila pengelompokan itu dilakukan oleh masyarakat muslim itu sendiri, dapat diartikan sebagai penghormatan terhadap tokoh-tokoh agama dari kelompok masyarakat muslim yang dimakamkan.

\section{PENUTUP}

Berdasarkan beberapa uraian di atas, di bawah ini akan disimpulkan beberapa hal yang berkaiatan dengan Kompleks Makam Troloyo.

Berdasarkan idetifikasi gaya penulisan dari tujuh buah makam dapat diketahui adanya dua gaya penulisan yaitu Naskhi dan Sulus. Secara kuantitatif gaya Naskhi lebih dominan. Sedangkan secara kualitatif hampir sama, sebab masing-masing gaya penulisan mempunyai dua katagori yang tidak jauh berbeda.

Melihat seluruh inskripsi yang ada, arti dan maksud pencantuman isi inskripsi berkaitan erat antara yang dimakamkan dengan pendukungnya yaitu kelompok masyarakat muslim selaku kelompok minoritas dalam Kerajaan Majapahit.

Berdasarkan angka-angka tahun yang tertera dapat diketahui bahwa angka tahun tertua berasal dari sebelum masa Majapahit. Selanjutnya diikuti masa awal Kerajaan Majapahit, melewati masa kejayaan sampai keruntuhannya.

Berdasarkan penelitian L. Ch. Damais terdapat satu buah makam yang menyebutkan nama yaitu Zayn ud-Din. Selebihnya tidak satupun yang mencantumkan nama orang. Tidak dicantumkannya nama tokoh atau nama orang yang meninggal, mungkin merupakan adaptasi dari budaya sebelumnya (Hindu) yang tidak mengenal adanya makam, tetapi diperabukan. 


\section{KEPUSTAKAAN}

Chawari, Muhammad. 1993. Laporan Hasil Penelitian Arkeologi Tentang Perkembangan Paleografi Arab Tabap I. Yogyakarta: Balai Arkeologi . Paleografi Arab Tahap II. Yogyakarta: Balai Arkeologi Yogyakarta.
- .ophangan

Damais, L.Ch. 1957. Etudes Javanaise I, Les Tombes Musulmanen Datees de Tralaya, BEFEO XIVVII.

Moquette,J.P.1912. De Datum op den Grafsteen van Malik Ibrahim te Gresik, TBG.

Pedoman Transliterasi Arab-Latin. Jakarta: Dikeluarkan Berdasarkan Keputusan Bersama Menteri Agama dan Menteri Pendidikan dan Kebudayaan Republik Indonesia No. : 158 tahun 1987 dan nomor: 0543b/U/1987.nomor: 158 tahun 1987 dan nomor: $0543 \mathrm{~b} / \mathrm{U} / 1987$.

Safadi, Yasin Hamid. 1986. Kaligrafi Islam (Terjemahan). Jakarta: Penerbit PT. Pantja Simpati, Cetakan I.

Sirajuddin, D. AR. 1985. Seni Kaligrafi Islam. Jakarta: Penerbit Pustaka Panjimas, Cetakan I.

Slametmulyana, Prof, Dr. 1979. Nagarakretagama Dan Tafsir Sejarahnya. Jakarta: Bhratara Karya Aksara.

Tjandrasasmita, Uka. 1976. Sepintas Mengenai Peninggalan Kepurbakalaan Islam Di Pesisir Utara Jowa, Aspek-aspek Arkeologi Indonesia No. 3. Jakarta: Pusat Penelitian Arkeologi Nasional.

Tjandrasasmita, Uka. 1992. Riwayat Penyelidikan Kepurbakalaan Islam di Indonesia, 50 Tahun Lembaga Purbakala Dan Peninggalan Nasional. Jakarta: Pusat Penelitian Arkeologi Nasional, Departemen Pendidikan dan Kebudayaan, Cetakan Kedua.

1993. Majapahit Dan Kedatangan Islam Serta Prosesnya, 700 Tahun Majapahit (1293 - 1993) Suatu Bunga Rampai. Surabaya: CV. Wisnu Murti, Edisi Kedua.

Umar, Hasyim. 1979. Sunan Giri dan Pemerintahan Ulama di Giri Kedaton. Kudus: Menara. 